\title{
Zerk eragiten du obesitatea duen pertsona bat metabolikoki osasuntsua izatea edo ez izatea?
}

\author{
(What makes an obese person to be metabolically healthy or unhealthy?)
}

\author{
Olaia Aguirre Rodríguez, ${ }^{1}$ Itziar Eseberri Barace*1,2,3
}

${ }^{1}$ Farmazia eta Elikagaien Zientziak Saila. Farmazia Fakultatea (UPV/EHU), Vitoria-Gasteiz

${ }^{2}$ Bioaraba Osasunaren Ikerketa Zentroa, Vitoria-Gasteiz

${ }^{3}$ CIBERobn, Instituto de Salud Carlos III, Madrid

\begin{abstract}
LABURPENA: Obesitatea osasun-arazo garrantzitsua bihurtu da XXI. mendean, mundu osoan milioika pertsonei eragiten diena. Obesitatearekin batera hainbat komorbilitate agertzen direla onartuta dago, eta horiek bizi-itxaropena murriztearekin lotzen dira. Hala ere, obesitatea pairatzen duten pertsona guztiengan ez da egoera hori antzeman; izan ere, ikusi izan da hainbatek obesitatearekin lotutako asaldura kardiometabolikoen aurrean babesa erakusten dutela. Obesitatea pairatzen duten baina komorbilitaterik ez duten horiek metabolikoki osasuntsuak diren obesoak (MOO) dira. Gaur egun, MOO kontzeptuaren definizioa aldatu egiten da iturri bibliografikoen arabera; hortaz, ez da oso zehatza. Gainera, MOO identifikatzeko irizpide unibertsalik ez dagoenez, prebalentzia-datuak nabarmen aldatzen dira ikerketen artean. MOO eta metabolikoki osasuntsuak ez diren obesoen (MOEO) artean hainbat ezberdintasun fisiologiko, funtzional eta patologiko identifikatu dira: MOOek, adibidez, intsulinarekiko sentikortasunari eusten diote, eta ez dute ez hipertentsiorik ez dislipemiarik pairatzen. Gainera, MOOak 2 motako diabetesaren, gaixotasun kardiobaskularren eta beste heriotza-kausen aurrean babestuta daudela ikusi izan da. Ezberdintasun horien erantzuleetako batzuk MOOen eta MOEOen artean ezberdina den erraietako gantzaren metaketa eta gantz-ehunaren disfuntzioa direla proposatu da. Ondorioz, gorputz-masaren indizea komorbilitateen eraginez agertuko diren konplikazioen larritasunarekin zuzenki erlazionatuta egon arren, gantz-metaketaren kokalekuak eta gantz-ehunaren disfuntzioak erlazio zuzenagoa dute obesitatearekin batera etorri ohi diren komorbilitateen garapenarekin.
\end{abstract}

HITZ GAKOAK: metabolikoki osasuntsuak diren obesoak, metabolikoki osasuntsuak ez diren obesoak, 2 motako diabetesa, gaixotasun kardiobaskularrak, erraietako gantza, gantz-ehunaren disfuntzioa.

\begin{abstract}
Obesity has become a major health problem in the 21st century, affecting millions of people around the world. It is assumed that obesity is accompanied by different comorbidities that are related to a reduction in life expectancy. However, this situation has not been seen in all people with obesity, since it has been observed that some obese people show protection against cardiometabolic disorders related to obesity, a condition known as metabolically healthy obesity (MHO). At present, the definition of $\mathrm{MHO}$ varies according to the bibliographic source used, so it is not very precise. Furthermore, in the absence of universal criteria for identification of $M H O$, prevalence data vary between investigations. Some physiological, functional and pathological differences have been identified between $M H O$ and metabolically unhealthy obesity $(M U O)$ : individuals with MHU, for example, retain insulin sensitivity and do not suffer from hypertension or dyslipidemia compared to MUO. In addition, people with $\mathrm{MHO}$ are protected against type 2 diabetes, cardiovascular disease and other causes of death. Some responsible for these differences are the accumulation of visceral fat and the dysfunction of the adipose tissue. Consequently, despite the fact that the body mass index is directly related to the severity of the complications derived from obesity-related comorbidities, it can be stated that fat location and adipose tissue dysfunction are even more directly related.
\end{abstract}

KEYWORDS: metabolically healthy obesity, metabolically unhealthy obesity, type 2 diabetes, cardiovascular disease, visceral fat, adipose tissue dysfunction.

\footnotetext{
* Harremanetan jartzeko / Corresponding author: Itziar Eseberri Barace. Farmazia eta Elikagaien Zientziak Saila. Farmazia Fakultatea, UPV/EHU. Unibertsitate pasealekua 7, 01006, Vitoria-Gasteiz. - itziar.eseberri@ehu.eus - https://orcid.org/0000-00015036-963X

Nola aipatu / How to cite: Aguirre Rodríguez, Olaia; Eseberri Barace, Itziar (2021). «Zerk eragiten du obesitatea duen pertsona bat metabolikoki osasuntsua izatea edo ez izatea?». Ekaia, 40, 2021, 89-108. (https://doi.org/10.1387/ekaia.22345).

Jasotze-data: 2020, abenduak 15; Onartze-data: 2021, martxoak 2.
}

ISSN 0214-9753 - eISSN 2444-3581 / (c) 2021 UPV/EHU

(7) $(-)$ Lan hau Creative Commons Aitortu-EzKomertziala-LanEratorririkGabe 4.0 Nazioartekoa lizentzia baten mende dago 


\section{SARRERA}

Gainpisua eta obesitatea osasunarentzat kaltegarria izan daitekeen gehiegizko edo ezohiko gantz-metaketa bezala definitzen dira [1]. Gorputz-masaren indizea (GMI) obesitatearen lehen baheketa azkarrerako erabiltzen da; pisua (kg-tan) altueraren (metrotan) karratuagatik zatitzean eskuratzen da. Osasunaren Mundu Erakundearen (OME) arabera, $25 \mathrm{~kg} / \mathrm{m}^{2}$ eta $29,9 \mathrm{~kg} / \mathrm{m}^{2}$ arteko GMIk gehiegizko pisua adierazten du, eta $30 \mathrm{~kg} / \mathrm{m}^{2}$-ko edo gehiagoko GMIk, aldiz, obesitatea [1]. Zehatzago, gorputzeko gantz-ehunekoa erabil daiteke obesitatea diagnostikatzeko; irizpide hori hartuta, obesitatea pairatzen duten pertsonatzat hartzen dira gizonezkoetan \% 25etik gorako eta emakumezkoetan \% 33tik gorako ehunekoak dituztenak [2]. Obesitatea osasun-arazo garrantzitsuenetarikoa bihurtu da XXI. mendean; izan ere, OMEren datuek adierazten dutenez, 2016. urtean 18 urte baino gehiagoko helduen \% 39k (1.900 milioi baino gehiagok) gainpisua pairatzen zuen, eta $\% 13 \mathrm{k}$ (650 milioi baino gehiagok) obesitatea [1].

Obesitateak beste patologien agerpena ekartzen du, besteak beste, gaixotasun kardiobaskularrak (GKB), intsulinarekiko erresistentzia (IR) eta 2 motatako diabetesa, hipertentsio arteriala, arnas aparatuko gaixotasunak (asma, loaldiko apnearen sindromea), urdail-hesteko gaixotasunak (errefluxu gastroesofagikoa, kasu), gibel gantzatsu ez-alkoholikoa eta esteatohepatitisa, dislipemiak, behazun edo giltzurrun kalkuluak, zenbait minbizi mota, larruazaleko gaixotasunak, osteoartritisa, obario polikistikoen sindromea edo gernu-inkontinentzia [3-5]. Bestalde, obesitatea pairatzen duten zenbait pertsonek nahasmendu psikiatrikoak (depresioa, batez ere) pairatzeko arrisku handiagoa dutela ikusi da, nahiz eta aurretik aipatutako patologiekin bezain estuki lotuta ez egon [6]. Azkenik, aipatzekoa da obesitateak bizi-itxaropena 20 urte inguru murrizten duela balioesten dela, obesitatearekin lotzen diren gaixotasunek hilkortasuna nabarmenki handitzen baitute [7].

Obesitatea pairatzen duten pertsonengan aipatutako komorbilitate horiek maiz agertzen badira ere, obesitatea pairatzen duten pertsona batzuek gaixotasun horiek garatzearen aurrean babesa erakusten dutela ikusi izan da; pertsona horiek «metabolikoki osasuntsuak diren obesoak» (MOO) dira [8].

\section{METABOLIKOKI OSASUNTSUA DEN OBESO KONTZEPTUAREN DEFINIZIOA}

Gaur egun, MOO identifikatzeko irizpideak ez daude unibertsalki onartuta. Edonola ere, onartzen da MOO obesitatea pairatzen duten, hots, GMI 
$30 \mathrm{~kg} / \mathrm{m}^{2}$ baino altuagoa duten, eta obesitatearekin lotutako alterazio metabolikorik pairatzen ez duten pertsonak izango direla [8]. Hala ere, definizio hori ez da oso zehatza, bereziki definizio horrek ez duelako alterazio metabolikoak zein diren zehazten. Hau da, alterazio metabolikorik izan beharrik ez dela onartzen den arren, autoreen artean iritzi kontrajarriak daude puntu honetan: autore batzuek soilik IR-ri egiten diote erreferentzia [9]; beste batzuek, berriz, 2 motako diabetesari, dislipemiei, hipertentsioari edo GKBei [7]. Gainera, GMI ez da obesitatea diagnostikatzeko neurririk zehatzena, ez baititu kontuan hartzen adina, sexua, gantz-masa edo gantzaren kokapena [8].

2018. urtean, MOO kontzeptuaren definizioa bateratzeko helburuarekin, beste definizio bat proposatu zen (1. taula), oraindik unibertsalki onartuta ez badago ere. Definizio horrek kontuan hartzen ditu, obesitateaz gain, odoleko triglizerido (TG) mailak, odoleko dentsitate altuko lipoproteinen (HDL) mailak, barauko glukosa-maila eta odol-presioa, MOO identifikatzeko garaian [10].

1. taula. MOO eta MOEO kontzeptuen definizioa. Lavie eta laguntzaileen lanetik moldatua [10].

\begin{tabular}{ll}
\hline \multicolumn{1}{c}{ MOO } & \multicolumn{1}{c}{ MOEO } \\
\hline $\begin{array}{l}\text { Pertsona bat «metabolikoki osasuntsua } \\
\text { den obesoa» izango da, obesitatea badu } \\
\left(\mathrm{GMI} \geq 30 \mathrm{~kg} / \mathrm{m}^{2}\right) \text { eta jarraian definitzen }\end{array}$ & $\begin{array}{l}\text { Pertsona bat «metabolikoki osasuntsua ez } \\
\text { den obesoa» izango da, obesitatea badu } \\
\text { diren sindrome metabolikoaren lau irizpi- }\end{array}$ \\
deetatik batere betetzen ez badu. & $\begin{array}{l}\text { koaren lau irizpideetatik bat edo gehiago } \\
\text { betetzen baditu. }\end{array}$ \\
\hline - Odoleko TG maila altuak & $\geq 150 \mathrm{mg} / \mathrm{dL}(1,7 \mathrm{mmol} / \mathrm{L})$ \\
\hline - HDL kolesterol-maila baxuak & $<40 \mathrm{mg} / \mathrm{dL}(1,0 \mathrm{mmol} / \mathrm{L})$ mutiletan \\
\hline- Odoleko presio altua & $<50 \mathrm{mg} / \mathrm{dL}(1,3 \mathrm{mmol} / \mathrm{L})$ nesketan \\
\hline- Barauko glukosa-maila altua & $\begin{array}{l}\text { Presio sistolikoa } \geq 130 \mathrm{~mm} \text { Hg edo/eta pre- } \\
\text { sio diastolikoa } \geq 85 \mathrm{~mm} \mathrm{HG}\end{array}$ \\
\hline $\begin{array}{l}\text { MOO: metabolikoki osasuntsuak diren obesoak; } \\
\text { soak; GMI: gorputz-masaren indizea; TG: triglizeridoak; HDL: dentsitate altuko lipoproteina. }\end{array}$
\end{tabular}

Luzetarako ikerketek frogatu dute osasun metabolikoa ez dela baldintza egonkorra, hau da, MOO direnak metabolikoki osasuntsuak ez diren obeso (MOEO) bihur daitezkeela [7]. Izan ere, 20 urteko jarraipena eta gero, MOOen \% 30-\% 50 inguru MOEO bihurtzen direla ikusi da [11]. Hala ere, Espainian egindako ikerketa baten arabera, bizi-ohitura osasunga- 
rriak berenganatuz (dieta osasungarria, jarduera fisikoa egitea, ez erretzea edo erretzeari uztea, kasu) metabolikoki osasuntsuak direnak ez-osasuntsu bihurtzea saihestu daiteke [12]. Bestetik, esku-hartze espezifikoen bidez MOEOak MOO bihur daitezkeela ere frogatu da [7]. Azkenik, hasierako pisuaren \% 5-\% 10 inguru murrizteak MOEOen osasun metabolikoa hobetu dezakeela ere ikusi da [13].

\section{PREBALENTZIA}

MOOen prebalentzia oso aldakorra da, eta ez guztiz fidagarria, fenotipo horren definizio estandarizatua falta delako [14]. Datuek erakusten dutenez, MOOen prebalentzia altuagoa izaten da emakumeengan, eta adinarekin murriztu egiten da [7]. Arrazaren edo etniaren arabera ere ikusi izan da aldakortasuna; badirudi Europako prebalentzia altuagoa dela Afrika, Hego Amerika eta Asiako hegoaldekoa baino [15]. Oro har, mundu mailako prebalentzia \% 10-\% 51 bitartekoa dela ikusi izan da [14].

Esan bezala, ikerlanetan datu oso aldakorrak eman dira; adibidez, Europan eta Estatu Batuetan egindako bi ikerketetan MOOen prebalentzia $\%$ 12-\% 17 bitartekoa dela ikusi zen $[16,17]$. Izan ere, ikerlan horietan, MOOtzat hartu ziren sindrome metabolikoaren irizpideetatik batere betetzen ez zuten pertsonak. Erresuma Batuan egindako ikerketa batean, aldiz, obesitatea pairatzen zuten pertsonen $\% 68 \mathrm{MOO}$ zirela adierazi zuten [18]. Ikerketa honetan, MOOen prebalentzia aurreko ikerlanetan ikusi dena baino askoz altuagoa da, MOO definitzeko presio arteriala edo odoleko glukosa zein lipidoen mailak kontuan hartu ez zirelako, hain zuzen. Egindako beste ikerketa batean, Holandako gizonezkoen \% 10 eta emakumezkoen \% $25 \mathrm{MOO}$ zirela ikusi zen, MOO sindrome metabolikorik gabeko pertsonak zirela kontuan hartuz [19].

\section{METABOLIKOKI OSASUNTSUAK DIREN OBESOEN EZAUGARRIAK}

MOO diren pertsonen eta MOEO direnen artean hainbat ezberdintasun fisiologiko, funtzional eta patologiko identifikatu izan dira (2. taula). MOOen fenotipoa aldez aurretiko joera genetikoarengatik, bizi-ohiturengatik edo bien nahasketarengatik gertatzen dela uste da [20]. Obesitatea pairatzen duten eta metabolikoki osasuntsuak diren pertsonak, normalean, gazteagoak dira, jarduera fisiko gehiago egiten dute, eta bihotz- eta arnas gaitasun hobea dute $[8,10]$. Dietari dagokionez, ez da alde nabaririk ikusi ingestio energetikoan edo makronutrienteen banaketan [15]. 
2. taula. MOOen eta MOEOen ezaugarrien arteko ezberdintasunak. Iacobini eta laguntzaileen eta Gonçalves eta laguntzaileen lanetatik moldatua [8, 20].

\begin{tabular}{ll}
\hline \multicolumn{1}{c}{ MOO } & \multicolumn{1}{c}{ MOEO } \\
\hline GMI $\geq 30 \mathrm{~kg} / \mathrm{m}^{2}$ & $\mathrm{GMI} \geq 30 \mathrm{~kg} / \mathrm{m}^{2}$ \\
Gazteagoa & Helduagoa \\
Intsulinarekiko sentikorrak & Intsulinarekiko erresistentzia \\
Odoleko presio normala & Hipertentsioa \\
Lipido profil onbera (TG maila $\downarrow$ eta HDL maila $\uparrow$ ) & Dislipemia (TG maila $\uparrow$ eta LDL maila $\uparrow$ ) \\
Erraietako eta lekuz kanpoko gantz gutxiago & Erraietako eta lekuz kanpoko gantz gehiago \\
Gantz-ehunaren funtzio normala & Gantz-ehunaren funtzio asaldatua \\
Adipokinen profil onbera & Adipokinen profil kaltegarria \\
Hantura-maila baxua & Hantura kronikoa \\
Gibel-funtzio normala & Gibel-funtzio asaldatua \\
Fisikoki aktiboagoa & Sedentarioagoa \\
Egoera nutrizional hobea & Egoera nutrizional okerragoa \\
\hline
\end{tabular}

MOO: metabolikoki osasuntsuak diren obesoak; MOEO: metabolikoki osasuntsuak ez diren obesoak; GMI: gorputz-masaren indizea; TG: triglizeridoak; HDL: dentsitate altuko lipoproteina; LDL: dentsitate baxuko lipoproteina.

MOOek ezaugarri metaboliko onuragarriak dituzte, batik bat 2 motako diabetesaren, GKBen eta beste heriotza-kausen aurreko babesa [7]. GKB termino zabala da, eta hainbat gaixotasun barnebiltzen ditu: kardiopatia koronarioa, bihotz-gutxiegitasuna, arritmiak, arteriopatia periferikoa edo istripu zerebrobaskularra, besteak beste [21]. Gaixotasun horiek, askotan, aterosklerosiaren ondorio dira: ateroma-plakak (gantza, kolesterola eta beste substantzien metaketa) arterien paretetan metatzearen ondorio dira [21]. Aterosklerosiaren garapenean odoleko HDL kolesterolaren maila baxuek eta TGen eta dentsitate baxuko lipoproteinen (LDL) maila altuek laguntzen dutela frogatu izan da [22, 23]. Denborarekin, plakek odol-hodiak estutu eta odol-fluxua zailtzen dute, eta, ondorioz, arazoak sortzen dira gorputz osoan [21].

2 motako diabetesa IR erakusteagatik ezaugarritzen da, eta ehunek intsulinaren estimulazioaren aurrean duten erantzun murriztu bezala definitzen da [24]. Pankreako $\beta$ zelulek jariatutako intsulinak zeluletan glukosaren absortzioa estimulatzen du, zeluletan biltegiratu eta, ondoren, energia iturri gisa erabiltzeko [25]. Hori horrela izanik, IR agertzen denean, muskuluko, gibeleko edo gantz-ehuneko zeluletan, besteak beste, glukosaren absortzioa murrizten da, hipergluzemia eraginez [24, 5]. 
IR-ren zein GKBren garapena azaltzen duten faktoreak asko dira. Horien artean daude gantz-metaketaren kokalekua eta gantz-ehunaren disfuntzioa, osasuntsuak diren eta osasuntsuak ez diren obesoen fenotipoen arteko ezberdintasunak ulertzen laguntzen duten faktoreak.

\subsection{Gantz-banaketak osasun metabolikoan duen eragina}

Kokalekuaren arabera, gantz-ehuna bitan sailka daiteke: larruazalpeko gantz-ehuna (larruazalaren azpian) eta erraietako gantz-ehuna (sabelaldean, organoak inguratuz) [26]. Normopisua duten eta elikadura-patroi osasungarria jarraitzen duten pertsonen gantz-biltegi nagusia larruazalpekoa da, eta erraietako gantz-ehunaren garapena, berriz, oso eskasa izaten da [27]. Obesitatean, larruazalpeko gantz-ehuneko lipidoen metaketa asko handitzen da, eta baita normopisuan daudenen kasuan oso txikia izaten den erraietako gantz-ehunekoa ere [27]. Gehiegizko pisua duten pertsonengan, larruazalpeko gantza hedatzeko gaitasuna murriztu egiten da, eta, ondorioz, adipozitoen biltegiratzeko gaitasuna gainditu eta gantza erraietako gantz-ehunean eta «lekuz kanpo» pilatzen da (gibela, muskulu eskeletikoa, pankreako $\beta$ zelulak, etab.), lekuz kanpoko gantza ehun ez-adiposoetan metatzen den gantz bezala ulertuz $[8,28,29]$. Ez-ohiko aldaketa horiekin batera, hantura, IR eta sindrome metabolikoaren beste ezaugarri batzuk ere agertu ohi dira [26]. Izan ere, obesitatea pairatzen duen pertsona batek gehiegizko gantz hori pilatzen duen lekuaren arabera, arazo metaboliko gehiago edo gutxiago izango ditu $[20,26]$.

\subsubsection{Erraietako gantzaren eragina}

Gorputzeko gantz-banaketan ezberdintasun nabariak antzeman daitezke MOOen eta MOEOen artean [7]. MOEOekin alderatuta, MOOen fenotipoa duten pertsonek larruazalpeko gantz gehiago eta erraietako zein lekuz kanpoko gantz gutxiago dute (gibelean, besteak beste).

Aspalditik jakina da gantz-ehunetik odolera askatzen diren esterifikatu gabeko gantz azidoen (EGGA) fluxua handitzeak erraietako gantzgordailuen handitzearen eta alterazio metabolikoen arteko lotura azaltzen duela (1. irudia) [30]. Erraietako gantz-ehunak larruazalpekoak baino jarduera lipolitiko handiagoa du, intsulina-hartzaile gutxiago izatean galdu egiten baita haren efektu antilipolitikoa, eta, hortaz, odolera jariatutako gantz azido askeen iturri garrantzitsua da [26]. Obesitatean, gehiegizko gantz-ehunak EGGA gehiago askatzeaz gain, haien argitzea (odoletik ezabatzea) murrizten da, eta odoleko EGGAen kontzentrazioa handitzea eragiten da [31, 32]. Gainera, EGGAek ere intsulinaren ekintza antilipolitikoa inhibitzen dute, eta zirkulaziora oraindik EGGA gehiago askatzea eragin [32]. Azken batean, EGGAen fluxua handitzeak lekuz kanpoko lipidoen metaketa eragin dezake, muskulu eskeletikoan eta gibelean batez 
ere [24]. Hori dela eta, lipotoxikotasunaren (gehiegizko gantza ehun ezadiposoan pilatzeak eragiten dituen ondorio toxikoak) ondorioz, IR bultzatu eta 2 motako diabetesa pairatzeko arriskua handitu egiten da hein handi batean [26, 33, 34], gehiegizko gantzak intsulinaren seinaleztapenean eragiten baitu [26,35]. Gainera, EGGAen kontzentrazio altuek muskulu eskeletikoan intsulinak eragindako glukosaren absortzioa inhibitzen dute, haren garraiatzailea den GLUT4ren mintz plasmatikorako translokazioa murrizten delako, eta baita glukogeno-sintesia eta glukosaren oxidazioa ere $[24,36]$. Oro har, obesitatea pairatzen duten pertsonen odoleko gantz azido askeen kontzentrazioa altua dela ikusi izan da [30], eta MOOetan, aldiz, baxuagoa [26, 37]. Hala eta guztiz ere, azpimarratzekoa da obesitatea pairatzen duten pertsonengan EGGAen kontzentrazio altuak ez daudela ezinbestean IR-ri lotuta [38].

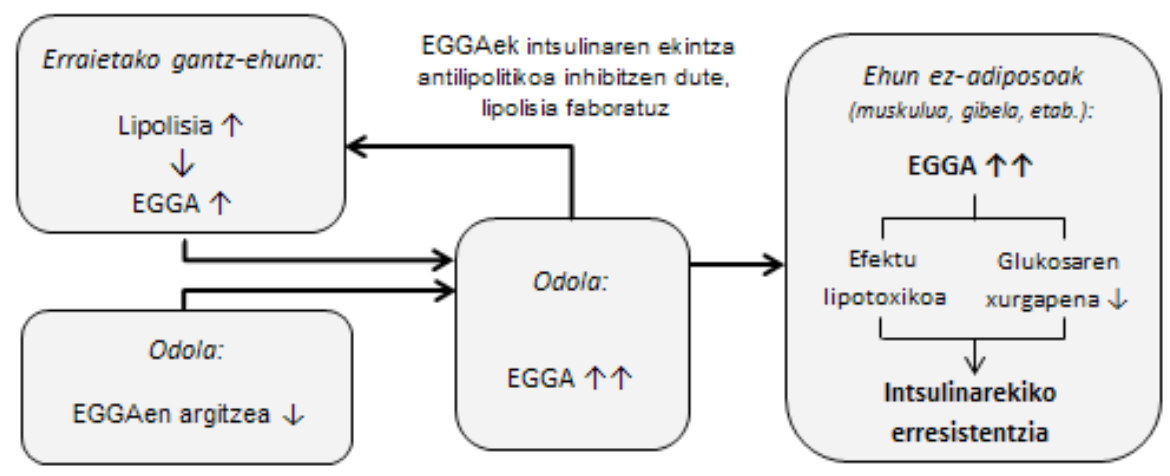

1. irudia. EGGAen fluxua handitzearen eta intsulinarekiko erresistentziaren arteko erlazioa azaltzeko proposatutako irudia. EGGA: esterifikatu gabeko gantz azidoak.

Bestalde, aipatu bezala, MOEOek GKB pairatzeko arrisku handiagoa dutela baieztatu izan da [7]. Izan ere, erraietako gantzak odolera askatzen dituen EGGAek eragin zuzena izan dezakete lipidoen metabolismoan, eta dislipemiak eragin ditzakete GKB pairatzeko arriskua areagotuz [26]. Horren arrazoia jarraian azalduko den EGGAen gibelerako fluxuan dago.

\subsubsection{Gibeleko gantzaren eragina}

Obesitatearekin batera, gibeleko gantza gehiegi pilatzea gertatu ohi bada ere [39], bi fenotipoetan ez da maiztasun berarekin gertatzen, eta horrek arrisku kardiobaskular desberdina izatea eragin dezake [20]. MOEOetan gibeleko gantzaren gehiegizko metaketa gertatu ohi da, odolera kantitate handietan isuritako EGGAk porta benatik gibelera heltzen baitira TGen sintesia faboratuz $[39,40]$. Bestalde, gibeleko gantz azidoen 
oxidazioa zein gibeletik odolera egiten den lipidoen isurketa murriztuta daude, eta lipogenesia handitua dago [39]. Horrek guztiak gibelean gantz gehiago metatzea ekartzen du, gibel gantzatsua, fibrosia eta esteatohepatitis ez-alkoholikoa eraginez [39, 41]. Gibel gantzatsua duten pertsonen gibelean oso dentsitate baxuko lipoproteinen (VLDL) eta LDLen jariatzea dago estimulatuta, eta HDL lipoproteinena txikiagoa da [42, 43]. Ondorioz, gibel gantzatsuak eragiten dituzten dislipemiek aterosklerosia faboratzen dute, GKB pairatzeko arriskua handituz (2. irudia) [42]. Gainera, gibeleko lipido-edukiaren eta gorputz osoko intsulinarekiko sentikortasunaren artean alderantzizko erlazioa dagoela ikusi izan da; argi geratu da gibeleko gantz-edukiak nabarmen eragiten duela 2 motako diabetesaren garapenean $[26,41]$.

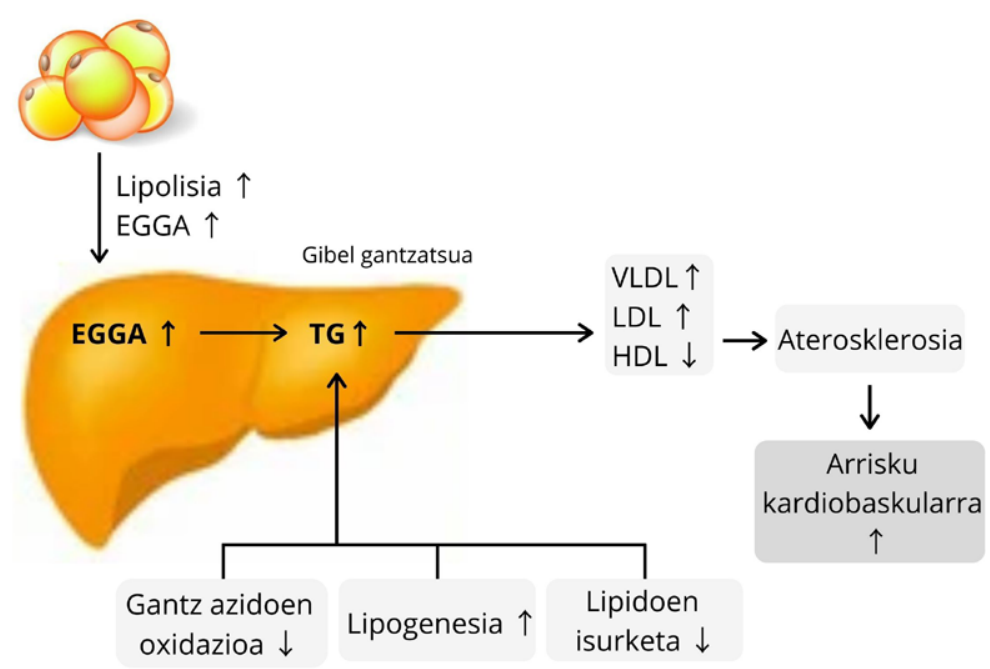

2. irudia. Gantz-ehunak odolera jariatutako EGGAek gaixotasun kardiobaskularren garapenean duten eragina azaltzeko proposatutako irudia. Eseberri eta laguntzaileen lanetik moldatua [39]. EGGA: esterifikatu gabeko gantz azidoak; TG: triglizeridoak; VLDL: oso dentsitate baxuko lipoproteina; LDL: dentsitate baxuko lipoproteina; HDL: dentsitate altuko lipoproteina.

\subsection{Gantz-ehunaren disfuntzioak osasun metabolikoan duen eragina}

Gantz-ehuna funtzio asko betetzen dituen organo endokrinoa da, bere funtzio nagusia gantzaren metaketa bada ere [44]. Helduen gantz-ehunaren masa adipozitoen tamaina handitzeak (hipertrofia) eta adipozitoen kopurua handitzeak (hiperplasia) zehazten dute [26, 45]. Helduen adipozito kopurua 
nahiko konstante mantentzen dela ikusi izan da, eta kopurua gehienbat haurtzaroan eta nerabezaroan finkatzen da. Hala ere, gorputz osoko adipozitoen $\% 10$ inguru urtero birsortzen dela balioesten da [45], eta horrek adierazten du adipozitoak sortzeak garrantzia duela helduaroan ere. Ingestio energetikoa altuegia denean, gantz-ehuna heda dadin, adipozitoek hipertrofia jasaten dute gehienbat - hain zuzen, ondorio metabolikoak ekar ditzakeen fenomenoa- [46]. Adipozitoen gehiegizko hipertrofiaren ondorioz, gantz-ehunaren disfuntzioaren barnean kokatzen den adipokinen jariaketa aztoratua gertatuko da, eta ondorio kaltegarriak eragingo ditu osasun metabolikoan [47]. Aipatzekoa da adipokinek, adipozitoek jariatutako seinalizazio-hormonek alegia, rol garrantzitsua dutela metabolismoaren erregulazioan; besteak beste, glukosaren metabolismoaren, intsulinaren jarioaren, hanturaren, gosearen eta asetasunaren arteko orekan edo energia-orekan $[11,48]$.

Bestetik, gantz-ehun zuriaren tamainaren eta ehunean infiltratuta dauden makrofagoen kopuruaren artean erlazioa dagoela ikusi izan da [45]. Hori horrela izanik, obesitatea pairatzen duten pertsonengan makrofago infiltratu gehiago daude normopisua duten pertsonengan baino. Makrofago horiek hanturaren aldeko zitokinak jariatzen dituzte, eta obesitatean gertatzen den maila txikiko hantura kronikoa faboratzen dute [45].

MOEOetan ez bezala, gantz-ehunaren funtzioak mantendu egiten dira MOOetan [20]. Gantz-ehunaren disfuntzioaren ezaugarriak dira, besteak beste, adipozitoen hipertrofia, lipidoen metabolismoaren asaldura, gantz-ehunaren odol-fluxua gutxitzea, adipozitoen zein gantz-ehuneko zelula immuneen zitokinen jariaketaren desoreka eta zelula immuneen infiltrazioa [29, 49-51]. Asaldura horiek maila txikiko hantura sistemikoa, odolean koaguluak sortzeko arriskua, presio arterial handitua, dislipemiak eta IR eragiten dituzte; hain zuzen ere, 2 motako diabetesaren eta GKBren garapenean eragiten duten faktoreak dira horiek [52].

\subsubsection{Adipozitoen tamainaren eragina}

Ezaguna da adipozitoen tamaina handitzea, hipertrofia alegia, gantzehunaren disfuntzioaren funtsezko ezaugarria dela [29]. Hipertrofiatutako adipozitoek EGGAen eta hanturaren aldeko adipokinen (Interleukina (IL) $6, \alpha$-tumore nekrosi-faktorea (TNF- $\alpha$ ), leptina eta kemerina, kasu) kantitate handiak ekoitz ditzakete; hanturaren kontrako adipokinen (adiponektina) ekoizpena, berriz, txikiagoa da [40, 52]. Gainera, gantz-ehun hipertrofikoa infiltraturiko zelula immune ugari izateagatik ezaugarritzen da [40,53]. Bestalde, adipozitoen gehiegizko hipertrofiak hipoxia eragingo $\mathrm{du}$; ondorioz, ehunaren fibrosia eta adipozitoen nekrosia ager daitezke, eta horrek gantz-ehunaren hantura fabora dezake [53]. Era berean, fibrosiak gantz-ehunaren hedatzeko gaitasuna murrizten du, eta lekuz kanpoko lipidoen metatzea faboratzen du [55]. 
Gantz-ehun disfuntzionalak 2 motako diabetesaren garapenean laguntzen duela ikusi izan da (3. irudia) [56]. Izan ere, gantz-ehun disfuntzionalaren ezaugarri diren adipozito hipertrofikoek EGGA, IL-6 eta TNF- $\alpha$ kantitate handiak askatzen dituzte, eta horiek interferentziak eragiten dituzte gibeleko eta muskulu eskeletikoko intsulinaren seinaleztapen-jauzian, IR eraginez [52]. Ondorioz, muskulu eskeletikoan glukosaren absortzioa eta glukogeno-sintesia murrizten dira, eta gibelean glukogenolisia handitu odoleko glukosa-mailaren kontrolerako. Aldaketa horiek guztiak eraginda, glukosarekiko intolerantzia garatuko da [52]. Bestalde, intsulinaren ekoizpena ere murriztu egiten da, IL-6k eta EGGAk pankreako $\beta$ zeluletan duten efektu toxikoen eraginez [57]. Glukosarekiko intolerantziaren, IR-ren eta intsulinaren jariapen baxuaren ondorioz, azken batean 2 motako diabetes bilakatuko da [52].

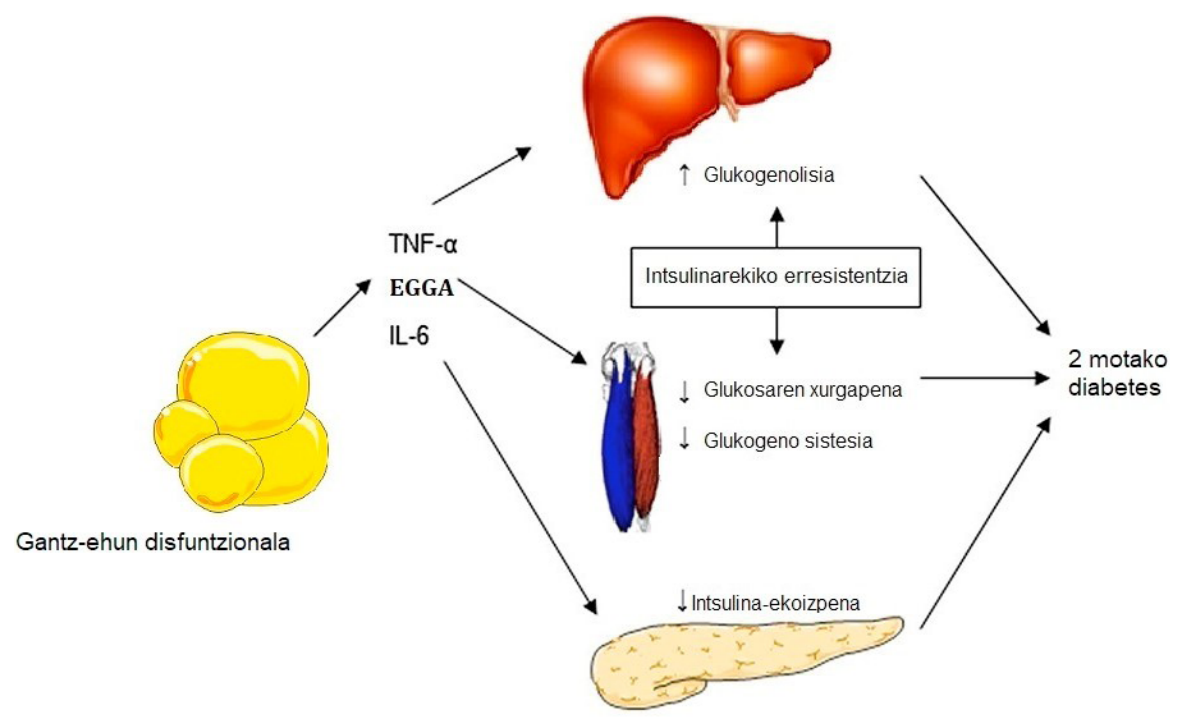

3. irudia. Gantz-ehun disfuntzionalak 2 motako diabetesa eragiten du. Schrover eta laguntzaileen lanetik moldatua [52]. TNF- $\alpha$ : $\alpha$-tumore nekrosi-faktorea; EGGA: esterifikatu gabeko gantz azidoak; IL-6: interleukina. 6.

Hortaz, argi dago adipozitoen tamainak garrantzi handia duela pertsona obesoen profil metabolikoan. MOEOetan adipozitoak tamaina handikoak dira, gehiago hipertrofiatzen direlako [29, 53]. MOOetan, berriz, adipozitoak tamaina txikiagokoak izaten dira, MOEOetan baino hiperplasia gehiago agertzen delako $[53,54]$. Esan beharra dago gantzehunaren hiperplasia osasungarritzat hartzen dela, adipozitoen funtzioak denbora gehiagoan mantentzen direlako bere horretan, aztoratu gabe $[46,54]$. 


\subsubsection{Adipokinen jario aztoratuaren eraginak}

Ehun adiposoak adipokina ugari ekoizten ditu, eta horiek, hainbat prozesu metaboliko ez ezik, hanturazko prozesuak ere erregulatzen dituzte [11]. Aipatu bezala, gantz-ehunaren disfuntzioaren eraginez adipokinen asaldatutako gehiegizko jariaketa gertatzen da; horrekin batera, gorputz osoko homeostasia aztoratzen da, eta arazo metabolikoak garatzen laguntzen du horrek [58]. Hori dela eta, ehun adiposoaren funtzio endokrinoa desorekatzea, besteak beste, IR-rekin eta GKBren garapenarekin lotzen da $[26,59]$.

MOOek eta MOEOek duten adipokinen profilari erreparatuz gero, kemerina, fibroblastoaren hazkuntza faktorea 21 (FGF21) eta adiponektina mailetan behatzen direla aldaketa nabarienak ikus daiteke [60]. Kemerina egoera metaboliko ez-osasuntsu batekin lotzen da [60], haren maila altuak sindrome metabolikoaren hainbat asaldurarekin erlazionatzen direla behatu baita; besteak beste, hipertriglizeridemia, hipertentsio arteriala eta 2 motako diabetesa [61, 62]. Izan ere, MOEO fenotipoa duten pertsonengan kemerinaren kontzentrazio altuagoa ikusi izan da [60]. FGF21i dagokionez, MOEOetan MOOetan baino maila altuagoak ikusi dira [63]; izan ere, egoera fisiologikoetan FGF21 hepatozitoek ekoizten badute ere, obesitatean gantz-ehunak ere ekoitz dezakeela ikusi da [26]. MOEOen ezaugarria den gibel gantzatsuak FGF21 maila altuak sortzen ditu, eta FGF21 kantitate altuek, aldi berean, gantz-ehunean adiponektinaren ekoizpena murrizten dute (4. irudia) [63]. Era berean, adiponektinak gibeleko FGF21en espresioaren inhibitzaile gisa jarduten duenez, FGF21ak eragindako hipoadiponektinemiak gibeleko FGF21aren ekoizpena handitzeko aukeraren hipotesia planteatu da, IR areagotzen duen autorregulazio-ziklo bat eratuz [63].

Bestetik, MOOek odoleko adiponektina-maila altuagoak dituztela ikusi izan da $[64,65]$. Adiponektina osasun metabolikoan eta kardiobaskularrean efektu positiboak dituen hanturaren kontrako adipokina da [27]. Gainera, adiponektinak gibeleko glukoneogenesia murrizten du, eta muskulu eskeletiko eta gibeleko gantz azidoen oxidazioa, muskulu eskeletikoaren glukosaren absortzioa eta gorputz osoko intsulinarekiko sentikortasuna handitzen ditu [26, 66]. Adiponektina-maila altuak dituzten pertsona obesoek odoleko glukosa, TG, intsulina eta hanturari erantzunez gibelak askatzen duen C proteina erreaktiboaren maila baxuagoak eta HDL kolesterolaren maila altuagoak dituzte [64], eta probabilitate handiagoa izango dute hanturamaila txikiagoa eta funtzio metaboliko hobetua izateko [65, 67]. Zeharkako ikerketa batean, adiponektina-maila baxuak eta erraietako gantz-masa hedatua IR pairatzeko arrisku handiagoarekin eta $\beta$ zelulen disfuntzioarekin lotu ziren [66]. Esan beharra dago kontraesanak daudela adiponektinak intsulinaren jariaketan dituen eraginen inguruan. Hala eta guztiz ere, badirudi odoleko adiponektina-maila altuek eragin babesgarria dutela obesitatearekin lotutako asaldura metabolikoen aurrean [64]. 


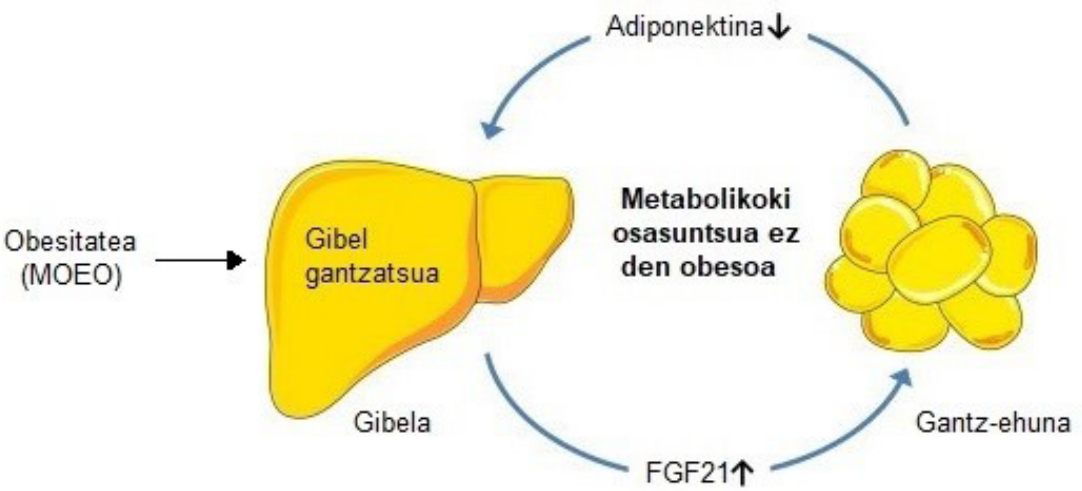

4. irudia. FGF21ek eta adiponektinak eragindako autorregulazio-zikloa deskribatzen duen eredu hipotetikoa. Berti eta laguntzaileen lanetik moldatua [63]. MOEO: metabolikoki osasuntsua ez den obesoa; FGF21: fibroblastoaren hazkuntza-faktorea 21 .

Aipatutako adipokinez gain, leptina-mailetan ere ezberdintasunak antzeman dira obesitatea duten pertsonen artean. MOOetan, orokorrean, MOEOetan baino odoleko leptina-maila baxuagoak behatu dira [67, 68], ikerketa batzuetan alde nabaririk ikusi ez den arren [65]. Adipokina horrek, jangura eta energia-gastua kontrolatzeaz gain, gantz-ehunean lipolisia estimulatu eta pankreako $\beta$ zelulen intsulinaren jarioa inhibitzen ditu. Gainera, efektu protronbotikoak eta prooxidatzaileak ditu [27]. Leptina-maila altuak dituzten pertsonek, GKB eta IR pairatzeko arrisku handiagoa izateaz gain, hantura-maila handiagoa eta profil metaboliko kaltegarriagoa erakusten dituzte $[67,69]$. Gainera, MOEOek leptinarekiko erresistentzia garatzen dutela ikusi izan da, eta, ondorioz, murriztuta izango dituzte leptinaren efektu fisiologikoak [68].

\subsubsection{Hantura-egoera MOO fenotipoan}

MOEOen fenotipoa gantz-ehunaren disfuntzioarekin lotzen da [20], eta, beraz, hanturaren aldeko eta kontrako adipokinen desorekarekin [52]. MOOek odoleko hanturaren kontrako adipokinen (adiponektina, IL-4, IL10 edo IL-13, kasu) maila altuagoak eta hanturaren aldeko adipokinen (leptina, erresistina, TNF- $\alpha$ edo IL-6) maila baxuagoak dituzte MOEOek baino $[20,70,71]$. Gainera, MOOek C proteina erreaktiboaren odolmaila baxuagoak eta gantz-ehunean infiltratutako makrofago gutxiago dituzte [20]. Hori horrela izanik, MOOen fenotipoa hantura sistemiko baxuagoa izateagatik ezberdintzen da [8]. 
MOOetan hiperplasia gehiago emateagatik gantz-ehunaren funtzioak denbora gehiagoz mantentzen direla kontuan hartuz [46], fenotipo hori duten pertsonek adipokinen ohiko jariaketa mantendu eta hantura-maila baxuagoa erakusten dutela ondoriozta daiteke [20]. Hantura-maila baxuago hori, gainera, GKB eta sindrome metabolikoaren ezaugarriak garatzeko arriskua murrizten duen faktore bat izan daitekeela uste da [20].

\section{MOO FENOTIPOA OSASUNTSUA AL DA?}

Garrantzitsua da azpimarratzea obesitatea pairatzen duten pertsonek, edozein fenotipo izanda, GKB pairatzeko arrisku handiagoa dutela normopisuan daudenek baino [13]. Horregatik, MOOen egoera metabolikoa MOEOena baino hobea izan daitekeela jotzen bada ere, ez da izango normopisua duten eta metabolikoki osasuntsuak diren pertsonena baino hobea (5. irudia) [7, 13]. Izan ere, MOOek normopisuan daudenek baino arrisku handiagoa dute GKB, gaixotasun zerebrobaskularrak, bihotz-hutsegitea, 2 motako diabetesa edo beste heriotza-kausa ohiko batzuk pairatzeko [7]. Bestalde, MOO metabolikoak ez diren beste ondorio batzuen aurrean ez daude babestuta; horien artean daude osteoartritisa, bizkarreko mina, arnas gaixotasunak, anomalia psikologikoak edo zenbait minbizi mota, bizi-kalitate okerragoa eragin dezaketenak [7, 29].

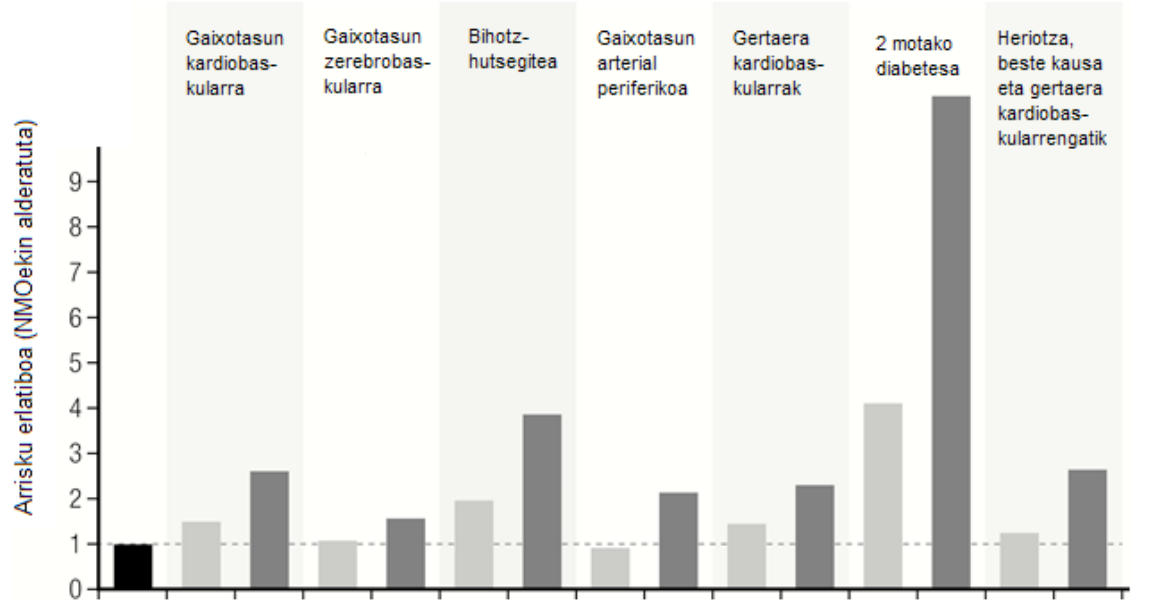

Normopisua duen eta metabolikoki osasuntsua den pertsona (NMO)

Metabolikoki osasuntsua den obesoa (MOO)

Metabolikoki osasuntsua ez den obesoa (MOEO)

5. irudia. Gaixotasun kardiobaskularra, 2 motako diabetesa edo bestelako heriotza-kausak pairatzeko arriskua. Blüher 2020 lanetik moldatua [7]. 
Laburbilduz, MOOek MOEOek baino GKB pairatzeko arrisku txikiagoa dutela ikusi bada ere, ez daude gaixotasun kardiometaboliko guztien aurrean babestuta; hortaz, ezin da gaixotasun onberatzat hartu [7]. Hori dela eta, MOOen fenotipoa ez da gaizki interpretatu behar, ezin baita hartu obesitatea pairatzen duten eta osasunean inolako kalterik ez duten pertsonen azpitalde gisa.

\section{LABURBILDUMA}

Ezaguna da, aspalditik, obesitateak beste gaixotasunak agertzea eragiten duela; hala ere, egun badakigu ez dela beti horrela izaten, gainpisua eta obesitatea pairatzen duten zenbait pertsonek babesa erakusten baitute hainbat komorbilitateren aurrean. Beraz, komorbilitateak garatzeko arriskua fenotipoen araberakoa dela esan daiteke. Honako irudi honek erakusten du bi fenotipoek dituzten ezberdintasun metabolikoek gaixotasunak garatzeko arriskuan duten eragina (6. irudia).

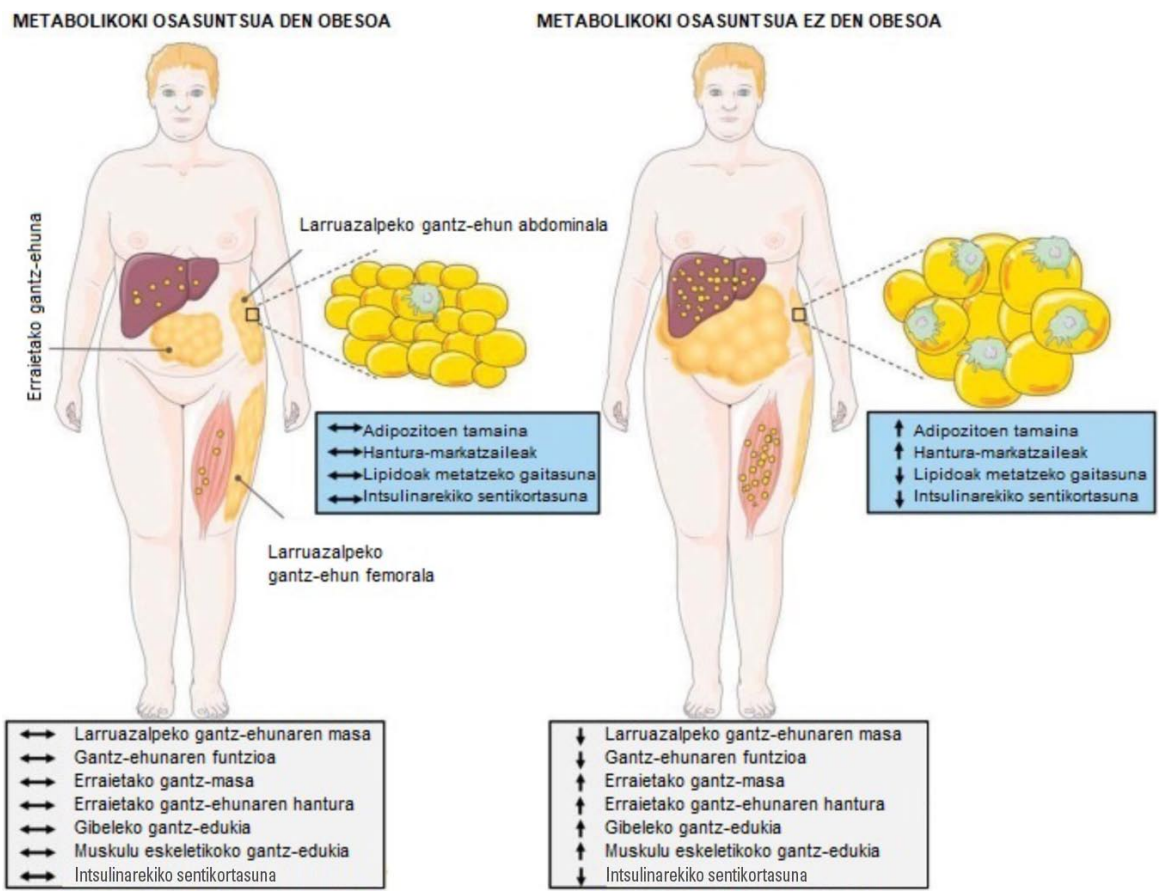

6. irudia. Gantz-ehunaren funtzioen eta gorputzeko gantzaren banaketaren arteko desberdintasunak MOOen eta MOEOen artean. Goosens 2017 lanetik moldatua [29]. 
Ikusitakoan oinarrituz, esan daiteke fenotipoen arteko ezberdintasunen erantzuleetako batzuk erraietako zein lekuz kanpoko gantzaren metaketa eta gantz-ehunaren disfuntzioa direla, eta horiek arazo kardiometabolikoen garapenarekin zuzenki erlazionatuta daudela ondoriozta daiteke. Argi dago, beraz, guztia ez dela gehiegizko pisua edo gantz-metaketa. Izan ere, obesitatea pairatzen duen pertsona baten profil metabolikoa eta koerikortasunak garatzeko arriskua iragartzeko garaian, oso garrantzitsua da gantz-ehunaren funtzioak mantentzen diren eta gorputzeko gantzaren kokalekua deskribatzea, faktore garrantzitsuak baitira gaixotasun metaboliko eta kardiobaskularretako arriskua determinatzeko.

Azkenik, aipatzekoa da MOOek 2 motako diabetesa eta GKB pairatzeko MOEOek baino arrisku txikiagoa duten arren, MOOek gehiegizko pisua ez duten pertsonek baino arrisku handiagoa dutela. Gainera, MOEOak bezala, MOOak ere beste gaixotasun ez-metaboliko batzuk pairatzeko arriskuan daude. Hori horrela izanik, MOOek ere obesitateari aurre egiteko tratamendua jarraitu beharko lukete, MOOen fenotipoa, MOEOen fenotipoa baino osasuntsuagoa izan arren, ezin baita osasuntsutzat hartu.

\section{BIBLIOGRAFIA}

[1] Organizaciín mundial de la Salud. Obesidad y sobrepeso. Eskuragarri: https://www.who.int/es/news-room/fact-sheets/detail/obesity-andoverweight . Eguneratze-data: 2020ko apirilak 1 (azken kontsulta: 2020ko irailak 15).

[2] Barbany, M., Foz, M. 2008. «Obesidad: Concepto, clasificacion y diagnostico». Anales del Sistema Sanitario de Navarra, 31, 7-16.

[3] Cabrerizo, L., Rubio, M.A., Ballesteros, M.D., Moreno, C. 2008. «Complicaciones asociadas a la obesidad ». Revista española de nutrición comunitaria, 14, 156-162.

[4] Schelbert, K.B. 2009. «Comorbidities of Obesity». Primary Care: Clinics in Office Practice, 36, 271-285.

[5] Andolfi, C., Fisichella, P.M. 2018. «Epidemiology of Obesity and Associated Comorbidities». Journal of Laparoendoscopic and Advanced Surgical Techniques, 28, 919-924.

[6] Fabricatore, A.N., Wadden, T.A. 2004. «Psychological aspects of obesity». Clinics in Dermatology, 22, 332-337.

[7] BLÜHER, M. 2020. «Metabolically Healthy Obesity». Endocrine Reviews, 41, 405-420.

[8] Iacobini, C., Pugliese, G., Blasetti, C., Federici, M., Menini, S. 2019. «Metabolically healthy versus metabolically unhealthy obesity». Metabolism: Clinical and Experimental, 92, 51-60.

[9] Асево, M. L. 2017. «Obesidad y salud, ¿en realidad existe el paciente obeso metabólicamente sano? ». Revista de Salud Pública y Nutrición, 16, 44-45. 
[10] Lavie, C.J., Laddu, D., Arena, R., Ortega, F.B., Alpert, M.A., KushNER, R.F. 2018. «Healthy Weight and Obesity Prevention: JACC Health Promotion Series». Journal of the American College of Cardiology, 72 , 1506-1531.

[11] Graf, C., Ferrari, N. 2019. «Metabolic health - the role of adipo-myokines». International Journal of Molecular Sciences, 20, 6159.

[12] Jung, C.H., LEE, W.J., Song, K.H. 2017. «Metabolically healthy obesity: A friend or foe?». Korean Journal of Internal Medicine, 32, 611-621.

[13] PhILliPS, C.M. 2013. «Metabolically healthy obesity: Definitions, determinants and clinical implications». Reviews in Endocrine and Metabolic Disorders, 14, 219-227.

[14] Rey, J.P., De Rezende, L.F., PAStor, M., Tess, B.H. 2014. «The prevalence of metabolically healthy obesity: A systematic review and critical evaluation of the definitions used». Obesity Reviews, 15, 781-790.

[15] Smith, G.I., Mittendorfer, B., Klein, S. 2019. «Metabolically healthy obesity: Facts and fantasies». Journal of Clinical Investigation, 129, 3978-3989.

[16] Van Vliet-Ostaptchouk, J. V., Nuotio, M. L., Slagter, S. N., Doiron, D., FISCHER, K., FOCO, L. et al. 2014. «The prevalence of metabolic syndrome and metabolically healthy obesity in Europe: A collaborative analysis of ten large cohort studies». BMC Endocrine Disorders, 14, 9.

[17] Ortega, F., Lee, D. C., Katzmarzyk, P., Ruiz, J., Sui, X., Church, T. et al. 2013. «The intriguing metabolically healthy but obese phenotype: cardiovascular prognosis and role of fitness». European Heart Journal, 34, 389-397.

[18] Caleyachetty, R., Thomas, G. N., Toulis, K. A., Mohammed, N., Gokhale, K. M., BALACHANDRAN, K. et al. 2017. «Metabolically Healthy Obese and Incident Cardiovascular Disease Events Among 3.5 Million Men and Women». Journal of the American College of Cardiology, 70, 1429-1437.

[19] Slagter, S. N., Corpeleijn, E., van der Klauw, M. M., Sijtsma, A., Swart-Busscher, L. G., Perenboom, C. W. M., et al. 2018. «Dietary patterns and physical activity in the metabolically (un)healthy obese: the Dutch Lifelines cohort study». Nutrition Journal, 17, 18.

[20] Gonçalves, C.G., Glade, M.J., Meguid, M.M. 2016. «Metabolically healthy obese individuals: Key protective factors». Nutrition, 32, 14-20.

[21] MedlinePlus. Qué es la enfermedad cardiovascular. Eskuragarri: https:// medlineplus.gov/spanish/ency/patientinstructions/000759.htm . Eguneratzedata: 2020ko urtarrilak 27 (azken kontsulta: 2020ko maiatzak 14).

[22] Lu, H., DAugherTy, A. 2015. «Atherosclerosis». Arteriosclerosis, Thrombosis, and Vascular Biology, 35, 485-491.

[23] Carvajal, C. 2015. «LDL oxidada y la aterosclerosis». Medicina Legal de Costa Rica, 32, 161-169.

[24] Ormazabal, V., Nair, S., Elfeky, O., Aguayo, C., Salomon, C., Zuñiga, F.A. 2018. «Association between insulin resistance and the development of cardiovascular disease». Cardiovascular Diabetology, 17, 122. 
[25] MeduinePlus. Diabetes tipo 2. Eskuragarri: https://medlineplus.gov/spanish/ ency/article/000313.htm . Eguneratze-data: 2020 ko urtarrilak 26 (azken kontsulta: 2020ko maiatzak 14).

[26] Chait, A., Den Hartigh, L.J. 2020. «Adipose Tissue Distribution, Inflammation and Its Metabolic Consequences, Including Diabetes and Cardiovascular Disease». Frontiers in Cardiovascular Medicine, 7, 22.

[27] REYES, M. 2012. «Características biológicas del tejido adiposo: el adipocito como célula endocrina». Revista Médica Clínica Las Condes, 23, 136-144.

[28] Kang, Y.M., Jung, C.H., Cho, Y.K., Jang, J.E., Hwang, J.Y., Kim, E.H. et al. 2017. «Visceral adiposity index predicts the conversion of metabolically healthy obesity to an unhealthy phenotype». PLOS ONE, 12, e0179635.

[29] Goossens, G.H. 2017. «The Metabolic Phenotype in Obesity: Fat Mass, Body Fat Distribution, and Adipose Tissue Function». Obesity Facts, 10, 207-215.

[30] TeiXeira, T., Alves, R., Moreira, A.P., Peluzio, M.D.C. 2015. «Main characteristics of metabolically obese normal weight and metabolically healthy obese phenotypes». Nutrition Reviews, 73, 175-190.

[31] Tumova, J., Andel, M., Trnka, J. 2016. «Excess of Free Fatty Acids as a Cause of Metabolic Dysfunction in Skeletal Muscle». Physiological Research, 65, 193-207.

[32] Boden, G. 2011. «Obesity, insulin resistance and free fatty acids». Current Opinion in Endocrinology, Diabetes and Obesity, 18, 139-143.

[33] Martinez, J., Durán, P.V., JuÁrez, M.A. 2013. «Los ácidos grasos y la lipotoxicidad: implicaciones metabólicas». Revista de la Facultad de Medicina de la UNAM, 56, 5-18.

[34] Yazici, D., Sezer, H. 2017. Obesity and lipotoxicity. Springer, New York.

[35] Hardy, O.T., CZECh, M.P., Corvera, S. 2012. «What causes the insulin resistance underlying obesity? ». Current Opinion in Endocrinology, Diabetes and Obesity, 19, 81-87.

[36] Preis, S.R., Massaro, J.M., Robins, S.J., HofFMann, U., VASAn, R.S., IrLbeCK, T. et al. 2010. «Abdominal Subcutaneous and Visceral Adipose Tissue and Insulin Resistance in the Framingham Heart Study». Obesity, 18, 2191-2198.

[37] Succurro, E., Marini, M.A., Frontoni, S., Hribal, M.L., Andreozzi, F., LAURO, R. et al. 2008. «Insulin Secretion in Metabolically Obese, but Normal Weight, and in Metabolically Healthy but Obese Individuals». Obesity, 16, 1881-1886.

[38] Karpe, F., Dickmann, J.R., Frayn, K.N. 2011. «Fatty acids, obesity, and insulin resistance: Time for a reevaluation». Diabetes, 60, 2441-2449.

[39] Eseberri, I., Milton-Laskibar, I., Aguirre, L., Fernández-Quintela, A., Portillo, M.P. 2020. «Gibel gantzatsu ez-alkoholikoa, xxi. mendeko osasun-arazoa». Ekaia, 37, 11-24.

[40] Gómez, S., Trepiana, J., Milton-Laskibar, I., Portillo, M.P. 2020. «Adipogenesia, osasunaren etsai edo lagun?». Ekaia. 
[41] Saponaro, C., Gaggini, M., Carli, F., Gastaldelli, A. 2015. «The subtle balance between lipolysis and lipogenesis: A critical point in metabolic homeostasis». Nutrients, 7, 9453-9474.

[42] Ballestri, S., Lonardo, A., Bonapace, S., B yrne, C.D., Loria, P., TARgher, G. 2014. «Risk of cardiovascular, cardiac and arrhythmic complications in patients with non-alcoholic fatty liver disease». World Journal of Gastroenterology, 20, 1724-1745.

[43] Gaggini, M., Morelli, M., Buzzigoli, E., DeFronzo, R.A., Bugianesi, E., GASTALDELLI, A. 2013. «Non-alcoholic fatty liver disease (NAFLD) and its connection with insulin resistance, dyslipidemia, atherosclerosis and coronary heart disease». Nutrients, 5, 1544-1560.

[44] Flores, J.R., RodrígueZ, E., Rivas, S. 2011. «Metabolic Consequences of the Functional Alterations of Adipose Tissue in Obese Patients». Revista medica del hospital general de Mexico, 7, 22.

[45] Esteve, M. 2014. «Adipose tissue: Cell heterogeneity and functional diversity». Endocrinología y Nutrición, 61, 100-112.

[46] SuÁrez, W., SÁnchez, A.J., GonzÁlez, J.A. 2017. «Fisiopatología de la obesidad: Perspectiva actual». Revista Chilena de Nutricion, 44, 226-233.

[47] Skurk, T., Alberti-Huber, C., Herder, C., Hauner, H. 2007. «Relationship between Adipocyte Size and Adipokine Expression and Secretion». The Journal of Clinical Endocrinology \& Metabolism, 92, 1023-1033.

[48] Hajer, G., Van Haeften, T., Visseren, F. 2008. «Adipose tissue dysfunction in obesity, diabetes, and vascular diseases». European Heart Journal, 29, 2959-2971.

[49] Goossens, G.H., BlaAK, E.E. 2015. «Adipose tissue dysfunction and impaired metabolic health in human obesity: A matter of oxygen?». Frontiers in Endocrinology, 6, 55.

[50] BLÜHER, M. 2013. «Adipose tissue dysfunction contributes to obesity related metabolic diseases». Best Practice and Research: Clinical Endocrinology and Metabolism, 27, 163-177.

[51] Trim, W., Thompson, D., Turner, J.E. 2018. Encyclopedia of Behavioral Medicine. Springer, New York.

[52] Schrover, I.M., Spiering, W., Leiner, T., Visseren, F.L. 2016. «Adipose Tissue Dysfunction: Clinical Relevance and Diagnostic Possibilities». Hormone and Metabolic Research, 48, 213-225.

[53] Milton, I., Portillo, M.P. 2020. «Adipozitoak, obesitatea eta osasuna: uste baino erlazio konplexuagoa». Elhuyar, 340, 82-85.

[54] Ghaben, A.L., Scherer, P.E. 2019. «Adipogenesis and metabolic health». Nature Reviews Molecular Cell Biology, 20, 242-258.

[55] EzQuerro, S, FrüHBEck, G, RodríGueZ, A. 2016. «El tejido adiposo, protagonista en las alteraciones metabólicas de la obesidad». Revista de la Sociedad Española de Bioquímia y Biología Molecular, 190, 23-28.

[56] Longo, M., Zatterale, F., Naderi, J., Parrillo, L., Formisano, P., RaCITI, G. A. et al. 2019. «Adipose tissue dysfunction as determinant of obesi- 
ty-associated metabolic complications». International Journal of Molecular Sciences, 20, 2358.

[57] Evans, J.L., Goldfine, I.D., Maddux, B.A., Grodsky, G.M. 2003. «Are oxidative stress - Activated signaling pathways mediators of insulin resistance and $\beta$-cell dysfunction? ». Diabetes, 52, 1-8.

[58] Unamuno, X., Gómez-Ambrosi, J., Rodríguez, A., Becerril, S., Frühbeck, G., CAtalán, V. 2018. «Adipokine dysregulation and adipose tissue inflammation in human obesity». European Journal of Clinical Investigation, 48, e12997.

[59] Landecho, M.F., Tuero, C., Valentí, V., Bilbao, I., de la Higuera, M., FRÜHBECK, G. 2019. «Relevance of leptin and other adipokines in obesityassociated cardiovascular risk». Nutrients, 11, 2664.

[60] Ebert, T., Gebhardt, C., Scholz, M., Wohland, T., Schleinitz, D., FasSHAUER, M. et al. 2018. «Relationship Between 12 Adipocytokines and Distinct Components of the Metabolic Syndrome». The Journal of Clinical Endocrinology \& Metabolism, 103, 1015-1023.

[61] Bozaoglu, K., Bolton, K., McMillan, J., Zimmet, P., Jowett, J., Collier, G. et al. 2007. «Chemerin Is a Novel Adipokine Associated with Obesity and Metabolic Syndrome». Endocrinology, 148, 4687-4694.

[62] HelFER, G., WU, Q.F. 2018. «Chemerin: A multifaceted adipokine involved in metabolic disorders». Journal of Endocrinology, 238, r79-r94.

[63] Berti, L., Irmler, M., Zdichavsky, M., Meile, T., BöHm, A., Stefan, N. et $a L$. 2015. «Fibroblast growth factor 21 is elevated in metabolically unhealthy obesity and affects lipid deposition, adipogenesis, and adipokine secretion of human abdominal subcutaneous adipocytes». Molecular Metabolism, 4, 519-527.

[64] Aguilar-Salinas, C.A., García, E., Robles, L., Riaño, D., Ruiz-Gomez, D.G., García-UlloA, A.C. et al. 2008. «High adiponectin concentrations are associated with the metabolically healthy obese phenotype». Journal of Clinical Endocrinology and Metabolism, 93, 4075-4079.

[65] AlfadDA, A.A. 2014. "Circulating Adipokines in Healthy versus Unhealthy Overweight and Obese Subjects». International Journal of Endocrinology, 2014, 170434.

[66] Moon, H.U., HA, K.H., HAN, S.J., KIM, H J., KIM, D.J. 2019. «The association of adiponectin and visceral fat with insulin resistance and $\beta$-cell dysfunction». Journal of Korean Medical Science, 34, e7.

[67] Jamar, G., Caranti, D.A., De Cassia Cesar, H., Masquio, D.C.L., BanDONI, D.H., PISANI, L.P. 2017. «Leptin as a cardiovascular risk marker in metabolically healthy obese: Hyperleptinemia in metabolically healthy obese». Appetite, 108, 477-482.

[68] Chang, C.S., Lu, Y.J., Chang, H.H., Hsu, S.H., Kuo, P.H., ShIEH, C C. et al. 2018. «Role of adiponectin gene variants, adipokines and hydrometrybased percent body fat in metabolically healthy and abnormal obesity». Obesity Research and Clinical Practice, 12, 49-61. 
[69] Berezina, A., Belyaeva, O., Berkovich, O., Baranova, E., Karonova, T., BAZHENOVA, E. et al. 2015. «Prevalence, Risk Factors, and Genetic Traits in Metabolically Healthy and Unhealthy Obese Individuals». BioMed research international, 2015, 548734.

[70] Cătoi, A.F., PÂrvu, A.E., Andreicuț, A.D., Mironiuc, A., Crăciun, A., CĂTOI, C. et al. 2018. «Metabolically healthy versus unhealthy morbidly obese: Chronic inflammation, nitro-oxidative stress, and insulin resistance». Nutrients, 10, 1199-1210.

[71] Primeau, V., Coderre, L., Karelis, A.D., Brochu, M., Lavoie, M.E., MesSIER, V. et al. 2011. «Characterizing the profile of obese patients who are metabolically healthy». International Journal of Obesity, 35, 971-981. 